\title{
Perinatal Depression and Anxiety in Women With Multiple Sclerosis
}

\author{
A Population-Based Cohort Study
}

Karine Eid, MD, Øivind Fredvik Torkildsen, MD, PhD, Jan Aarseth, PhD, Heidi Øyen Flemmen, MD, Trygve Holmøy, MD, PhD, Åslaug Rudjord Lorentzen, MD, PhD, Kjell-Morten Myhr, MD, PhD, Trond Riise, PhD, Cecilia Simonsen, MD, Cecilie Fredvik Torkildsen, MD, Stig Wergeland, MD, PhD, Johannes Sverre Willumsen, MD, Nina Øksendal, MD, Nils Erik Gilhus, MD, PhD, and Marte-Helene Bjørk, MD, PhD

Neurology ${ }^{\circledR}$ 2021;96:e2789-e2800. doi:10.1212/WNL.0000000000012062

\section{Abstract \\ Objective}

To assess the occurrence of perinatal depression and anxiety in women before and after diagnosis of multiple sclerosis (MS).

\section{Methods}

A total of 114,629 pregnant women were included in the Norwegian Mother, Father and Child Cohort study (1999-2008). We assessed depression and anxiety by questionnaires during and after pregnancy. Women with MS were identified from national health registries and hospital records and grouped into (1) MS diagnosed before pregnancy $(\mathrm{n}=140)$ or MS diagnosed after pregnancy with (2) symptom onset before pregnancy $(\mathrm{n}=98)$ or $(3)$ symptom onset after pregnancy $(n=308)$. Thirty-five women were diagnosed with MS in the postpartum period. The reference group $(n=111,627)$ consisted of women without MS.

\section{Results}

Women with MS diagnosed before pregnancy had an adjusted odds ratio of 2.0 (95\% confidence interval, 1.2-3.1) for depression in the third trimester. Risk factors were adverse socioeconomic factors and history of psychiatric disease and physical/sexual abuse. The risk of anxiety was not increased. Women diagnosed with MS in the postpartum period had especially high risk of postpartum depression. Women with MS symptom onset within 5 years after pregnancy had increased risk of both depression and anxiety during pregnancy, whereas women with more than 5 years until symptom onset did not.

\section{Conclusion}

Women diagnosed with MS have increased risk of perinatal depression. Women with MS symptom onset within 5 years after pregnancy have increased risk of both depression and anxiety during pregnancy.

\author{
Correspondence \\ Dr. Eid \\ karine.eid@uib.no
}

\section{RELATED ARTICLE}

Editorial

Perinatal Depression and

Anxiety in Multiple

Sclerosis: Treatable

Distress

Page 1067

\section{MORE ONLINE}

Infographic

http://links.lww.com/WNL/

B412

CME Course

NPub.org/cmelist 


\section{Glossary}

aOR = adjusted odds ratio; $\mathbf{C I}=$ confidence interval; EPDS = Edinburgh Postnatal Depression Scale; HPA = hypothalamicpituitary-adrenal axis; HSCL-25 = Hopkins Symptom Checklist 25; LTMD = lifetime history of major depression; MBRN = Medical Birth Registry of Norway; MoBa = Norwegian Mother, Father and Child Cohort Study; MS = multiple sclerosis; MSR = Norwegian Multiple Sclerosis Registry and Biobank; NPR = Norwegian Patient Registry; OR = odds ratio; REK = Regional Committee for Medical and Health Research Ethics; SCL-4A = Symptom Checklist 4-item anxiety subscale; SCL4D = Symptom Checklist 4-item depression subscale.

People with multiple sclerosis (MS) have an increased prevalence of depression and anxiety compared to the general population. ${ }^{1}$ Several factors contribute, including pathobiological mechanisms of MS itself. ${ }^{2,3}$ Perinatal depression is the most common complication of pregnancy and is often underrecognized. It is defined as depression during pregnancy and up to 1 year after birth. ${ }^{4-6}$

There is limited knowledge of the occurrence of depression and anxiety in the perinatal setting among women with MS. One study found that $26 \%$ of mothers and fathers with MS had depression or anxiety in relation to pregnancy, ${ }^{7}$ compared to $19 \%$ of parents without MS. Psychiatric comorbidity in mothers influence mental health and developmental vulnerability in children. ${ }^{8-10}$ Because mothers with MS are at increased risk of depression and anxiety, it is important to identify risk factors associated with these symptoms in the perinatal setting to provide optimal prevention, treatment, and follow-up for women at risk.

Our primary aim was to investigate the occurrence of depression and anxiety during pregnancy and 6 months postpartum. We studied (1) women with an established MS diagnosis, (2) women who had experienced MS symptoms but not yet received a diagnosis, and (3) women with clinical MS symptom onset in the subsequent months or years after giving birth. The last 2 groups were included as they might have had subclinical or prodromal manifestations of MS during the perinatal period. ${ }^{11-13}$ Our secondary aim was to investigate to what degree MS-related factors and psychosocial aspects influenced the occurrence of these symptoms.

\section{Methods}

\section{Study Design and Population}

This is a prospective, population-based cohort study that includes women participating in the Norwegian Mother, Father and Child Cohort study (MoBa). The MoBa study is conducted by the Norwegian Institute of Public Health and is linked to the Medical Birth Registry of Norway (MBRN), to which registration is mandatory for Norwegian health care providers. ${ }^{14}$ Participants were recruited from all over Norway from 1999 through 2008. All Norwegian-speaking women were invited to the study after the routine ultrasound examination in pregnancy week 15-17. There were no exclusion criteria. In total, 50 of 52 maternity units with over 100 births per year participated, and $41 \%$ of the invited women consented to participation. Follow-up of the cohort is ongoing. Our current study is based on version 12 of the qualityassured data files released for research on September 5, 2019.

We obtained information on demography, socioeconomic factors, medical history, and symptoms of anxiety and depression by self-completed questionnaires. We used the questionnaires answered during pregnancy weeks $17-20$ and 30 , and 6 and 18 months postpartum.

The MS diagnoses reported in the questionnaires were validated through data linkage with the Norwegian Multiple Sclerosis Registry and Biobank (MSR), which also provided information on MS subtype and date of symptom onset and diagnosis. ${ }^{15}$ The MSR had 60\% coverage of MS cases in Norway at the time of linkage. To validate cases not registered in MSR, the cohort was linked to the Norwegian Patient Registry (NPR). The registration of patients in NPR is mandatory for health practitioners, and all consultations with an MS diagnosis in Norwegian specialist care have been registered since March 2007 (data available from Dryad, figure e-1, doi. org/10.5061/dryad.g4f4qrfpkv). The MS diagnosis in NPR has previously been validated, with a sensitivity of $97 \%$ and positive predictive value $0.92 .{ }^{16}$ MS diagnoses registered in NPR, but not in the MSR, were validated with information from hospital records using the 2017 diagnostic criteria for MS. ${ }^{17}$

The linkage between health registries made it possible to identify women with MS who failed to report a history of MS at inclusion in MoBa, as well as women diagnosed with MS after pregnancy. We followed these women until December 31, 2018. To differentiate between women with early symptomatic yet undiagnosed MS and women with inactive (preclinical) disease during pregnancy, we divided those diagnosed with MS after pregnancy according to the timing of their first MS symptoms. Hence, we defined 3 main groups: (1) MS diagnosed before pregnancy, (2) MS diagnosed after pregnancy with symptom onset before pregnancy, (3) MS diagnosed after pregnancy with symptom onset after pregnancy (figure 1). The reference group consisted of all women in MoBa without MS.

We also defined a subgroup of women who were diagnosed with MS during the first 18 months after pregnancy. In 
Figure 1 Multiple Sclerosis (MS) Diagnosis and Symptom Onset in Relation to Pregnancy and Childbirth

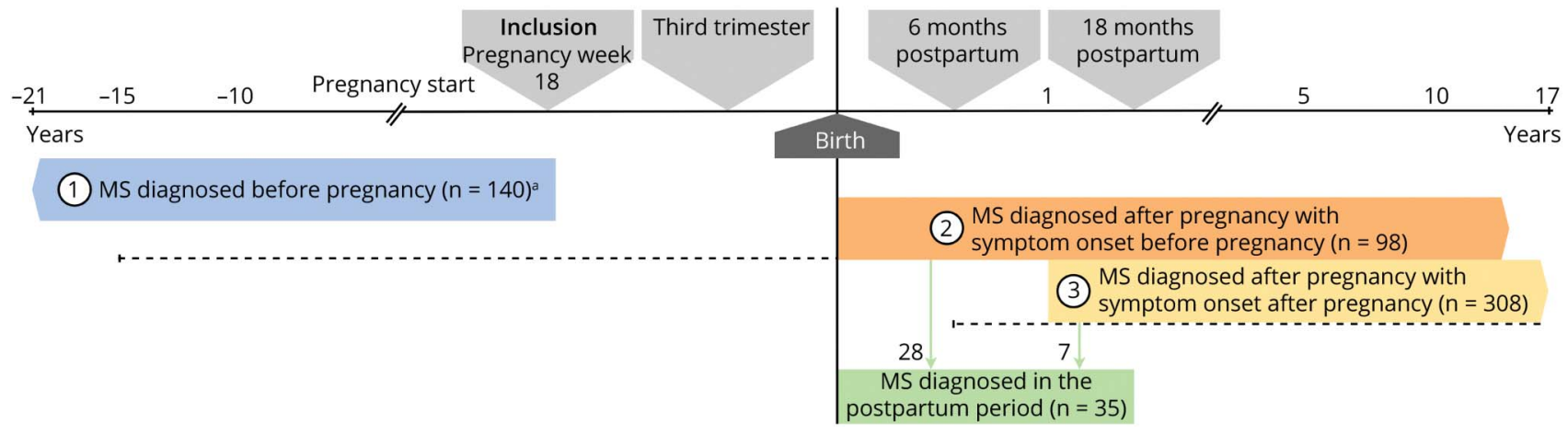

We identified 546 women with MS from the Norwegian Mother, Father and Child Cohort (MoBa). Women were divided into 3 groups defined by their MS status on inclusion. The periods of established MS diagnosis are illustrated by colored arrows. Periods of symptom onset are shown with dotted lines for the groups with MS diagnosed after pregnancy. We also studied a subgroup of women who were diagnosed with MS in the postpartum period (0-18 months). ${ }^{\text {a }}$ S diagnosed up to pregnancy weeks 18-20.

addition to being compared with the reference group, these women were also compared with a subgroup of the reference group that reported, at the 18-month assessment, that they had been diagnosed with a chronic disease other than MS during the last 12 months.

We excluded women with uncertain or refuted MS diagnosis, pregnancies with missing child number, and duplicate questionnaires from multiple gestations to include only one observation per pregnancy (figure 2). Women who were pregnant 18 months postpartum were excluded from the analysis at 18 months after birth.

\section{Primary Outcome Measure}

Depression and anxiety were measured separately by validated short versions of the Hopkins Symptom Checklist 25 (HSCL-25). ${ }^{18-20}$ These are widely used screening tools designed to detect depression and anxiety. The subscale SCL-

Figure 2 Flowchart of Excluded and Included Cases

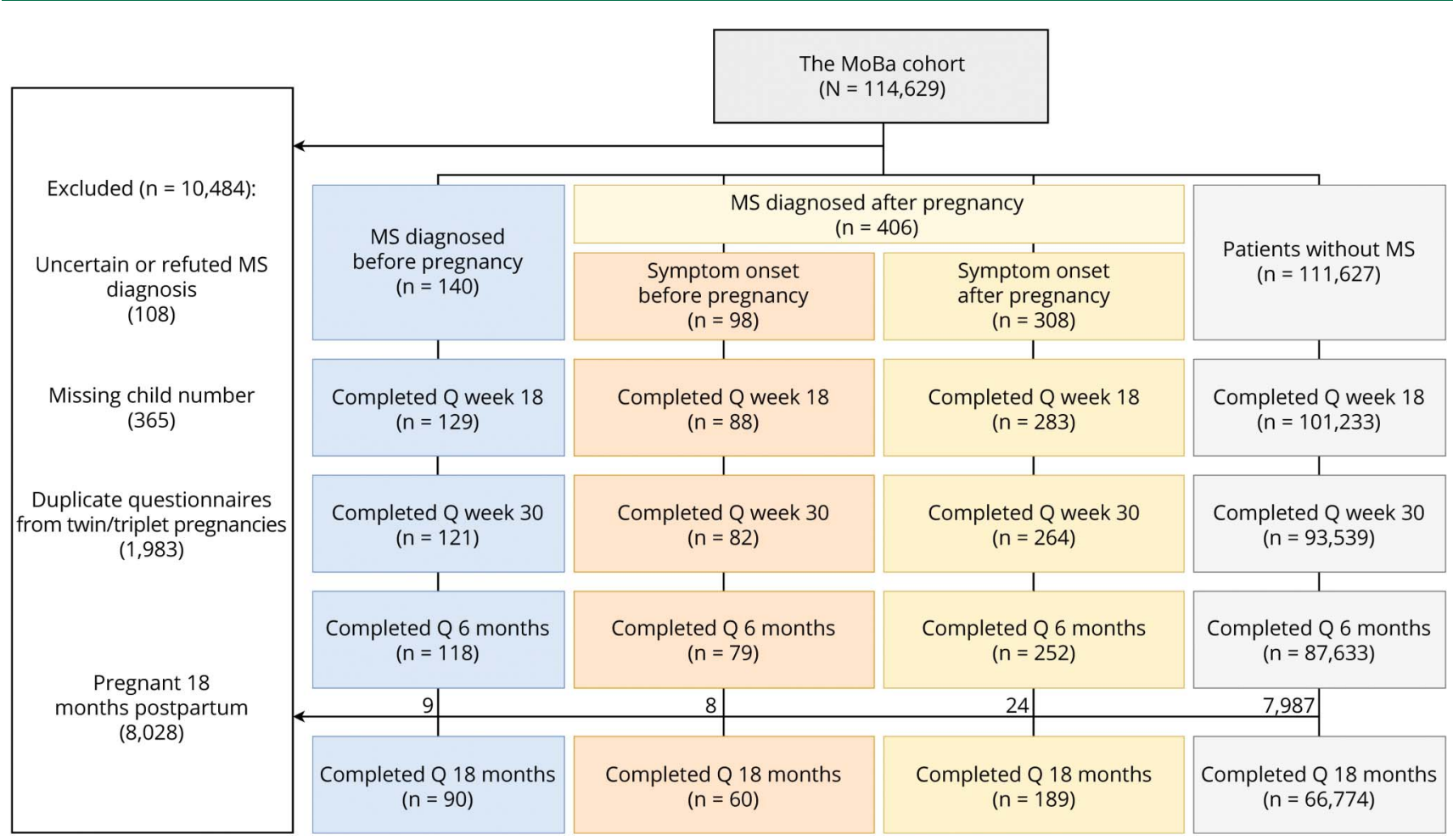

Pregnancies included in the Norwegian Mother, Father and Child Cohort (MoBa) study version 12. MS = multiple sclerosis; $\mathrm{Q}=$ questionnaire. 
8 includes 4 items capturing symptoms of depression (SCL4D) and 4 capturing symptoms of anxiety (SCL-4A), screening for symptoms during the last 2 weeks before assessment (data available from Dryad, e-Questionnaire, doi. org/10.5061/dryad.g4f4qrfpkv). Items were scored on a Likert scale ranging from 1 ("not at all bothered") to 4 ("very much bothered"). We used a validated mean score of $>1.75$ as cutoff for presence of depression or anxiety, respectively. ${ }^{18,21}$ SCL- 8 was used in pregnancy week 30 and 6 and 18 months postpartum. We defined perinatal depression or anxiety as symptoms occurring during pregnancy or in the postpartum period up to 6 months after birth. The proportion of women with symptoms was interpreted as the point prevalence of either depression or anxiety. Scores from the 18-month assessment were used as a prognostic measure for women with MS before pregnancy (group 1) and as point prevalence for those diagnosed with MS 0-18 months after birth.

Postpartum depression based on SCL-4D scores 6 months after birth was validated with a 6-item version of the Edinburgh Postnatal Depression Scale (EPDS-6) ${ }^{22}$ with a threshold score of $\geq 7 / 18$ defining postpartum depression. ${ }^{23}$ The kappa agreement between SCL-4D and EPDS- 6 was $88 \%$ within the MS groups in this study, with a coefficient of 0.52 . A prior validation of the entire MoBa cohort showed 91\% overall agreement of SCL-4D and EPDS- 6 at 6 months postpartum. ${ }^{24}$

\section{Covariates}

MS-specific covariates were assessed from the MSR and hospital records: time of MS onset, defined as first clinical symptom; time of MS diagnosis; and subtype of MS (relapsing-remitting MS, primary progressive MS, or unspecified) at disease onset. Relevant covariates that have been identified as possible risk factors for perinatal depression ${ }^{25,26}$ were selected from the MoBa questionnaires and the MBRN: maternal age at inclusion, parity (pregnancies $>24$ gestational weeks), low household income ( $<60 \%$ of median income in the given year), short education ( $\leq 9$ years), single mother, unplanned pregnancy, overweight (prepregnancy body mass index $>25)$, smoking and alcohol use during pregnancy $(\geq 1$ consumption per month for each), and disability benefits such as social security disability or work assessment allowance. Comorbidities included asthma, prepregnancy hypertension, renal disease, rheumatoid arthritis, type 1 diabetes, and epilepsy, which are the available diagnoses in the MBRN and registered by health personnel. Adverse pregnancy events were defined as a prior history of stillbirth or miscarriage past 12 weeks, prior or current preeclampsia, and first trimester vaginal bleeding. Adverse life events were defined as having experienced one of the following and defining it as "painful or difficult" during the last 12 months: conflict at work or study, financial problems, divorce/separation/partnership breakup, conflict with family or friends, severe injury or illness in the woman herself or a loved one, severe traffic accident, fire or robbery, or death of a close relative or friend. Lifetime physical and sexual abuse was evaluated by questions adapted from the
Abuse Assessment Screen. ${ }^{27}$ A history of major depression was assessed by the lifetime major depression score (LTMD). ${ }^{28}$ Previous history of anxiety was self-reported in the questionnaire in pregnancy week 18. Use of antidepressants during pregnancy was self-reported in pregnancy weeks 18 and 30. A combined score of anxiety and depression (SCL5) was used in pregnancy week 18 to evaluate early pregnancy psychiatric symptoms.

\section{Statistical Analysis}

IBM SPSS Statistics software version 26 was used to make variables and imputations. Stata version 16 was used in the remaining analyses.

The different MS groups were compared to a reference group of all women without MS in MoBa. Matching was not performed. Continuous variables were analyzed with Student $t$ test when normally distributed and skewed data with the Mann-Whitney $U$ test. Categorical variables were compared with the Pearson $\chi^{2}$ test or with Fisher exact test if any crosstable cell had an expected count $<5$. We analyzed the risk of depression and anxiety by logistic regression with estimated odds ratios (ORs) and 95\% confidence intervals (CIs). OR estimates were adjusted for the possible confounders age, parity, overweight, and adverse socioeconomic factors $(\geq 1$ of the following: single mother, low household income, or short education). We accounted for clustering among women with more than 1 pregnancy $(n=14,379)$ with robust standard error estimations. Estimates with CIs not including 1 were considered statistically significant.

\section{Secondary Outcome}

For women with diagnosed MS before pregnancy and women in the reference group, we manually performed a backward stepwise logistic regression analysis with third trimester depression as the dependent variable and a list of 17 independent variables as potential predictors (data available from Dryad, table e-1, doi.org/10.5061/dryad.g4f4qrfpkv). The alpha to enter the multivariate model was $\leq 0.1$ and alpha for variable removal was $\geq 0.05$. To evaluate whether the predictors differed between women with MS and the reference group we included relevant interaction terms in the model.

\section{Imputation of Missing Values}

The missing values analysis procedure in SPSS with the expectation-maximization algorithm was used to impute missing values when some of the SCL or LTMD items were not completed. Our requirements for imputation were that maximum 1 in 5 items (20\%) was missing in SCL-5 and maximum 3 of the $8(38 \%)$ in SCL-8. In LTMD, the first and sixth item had to be completed, and maximum 2 of 6 items (33\%) missing to allow for imputation. If these requirements were exceeded, the cases were set as missing.

\section{Sensitivity Analyses}

Various cutoff points for the subscales of HSCL-25 have been suggested. ${ }^{19}$ We therefore did a sensitivity analysis of severe 
depression with a high cutoff for depression in the third trimester, defined as SCL-4D score greater than the population mean +2 SD.

One of the items in SCL-4D, "Have you been bothered by ... feeling everything is an effort?" can be interpreted as a proxy of fatigue, which is a common symptom in MS. ${ }^{29}$ As MSrelated fatigue could influence this part of the depression score, the distribution of the answers to this question was analyzed with the $\chi^{2}$ and Fisher exact test, comparing the MS groups with the reference group. The answers to this question did not differ between women with MS diagnosis before pregnancy and women without MS.

\section{Standard Protocol Approvals, Registrations, and Patient Consents}

The establishment and initial data collection in MoBa were based on a license from the Norwegian Data Protection Agency and approval from the Regional Committees for Medical and Health Research Ethics (REK). The MoBa cohort is regulated by the Norwegian Health Registry act.

The current study was approved by REK (reference 2016/ 906). Written informed consent for use of the information in research and for data linkage was obtained during enrollment from all participants in MoBa and MSR.

\section{Data Availability}

Enquiries regarding access to data from $\mathrm{MoBa}$ and the MBRN can be directed to the Norwegian Institute of Public Health. Data from the MSR are accessible for researchers by application (norskmsregister.no).

\section{Results}

\section{Cohort}

The cohort consisted of 114,629 pregnant women (figure 2). Of these women, 546 were diagnosed with MS and divided into 3 groups:

1. One hundred forty women were diagnosed with MS before pregnancy

2. Ninety eight women were diagnosed with MS after pregnancy and had symptom onset before pregnancy

3. Three hundred eight women were diagnosed with MS after pregnancy and had symptom onset after pregnancy

Women who did not develop MS during the follow-up period $(\mathrm{n}=111,627)$ served as the reference group and had a median follow-up time of 13 years (range 9-19).

Women in group 2 had experienced their first MS symptom years or months before pregnancy (figure 1). However, they were undiagnosed at inclusion and had a median time of 4 years to MS diagnosis after pregnancy (table 1). Women in group 3 experienced their first MS symptom up to 17 years after pregnancy, with a median of 6 years until symptom onset. Median follow up-time for women with MS diagnosed after pregnancy was 7 years (range $0-17$ ).

The characteristics of women diagnosed with MS before pregnancy and the reference group were similar for socioeconomic and lifestyle factors and previous anxiety and depression (table 1). However, women diagnosed with MS before pregnancy were older and more likely to receive disability benefits. Compared to the reference group, women who had experienced MS symptoms but were not yet diagnosed with MS (group 2) more often had planned pregnancies and were more likely to smoke during pregnancy. Women who had their first MS symptom after pregnancy (group 3) were younger, more often overweight, more frequently smoked during pregnancy, and had experienced more physical or sexual abuse compared to the reference group.

Dropout rates in $\mathrm{MoBa}$ at 6 and 18 months postpartum among the women who screened positive for depression in the third trimester were similar for all examined groups (data available from Dryad, table e-2, doi.org/10.5061/dryad. g4f4qrfpkv).

\section{Women Diagnosed With MS Before Pregnancy}

A total of $15 \%$ of women diagnosed with MS before pregnancy had depression in the third trimester compared to $9 \%$ in the reference group without MS (table 2). The crude OR was 1.8 (95\% CI, 1.1-2.9). The OR was 2.0 (95\% CI, 1.2-3.1) after adjusting for age, parity, overweight, and socioeconomic factors.

The increased risk was confirmed in the sensitivity analysis when we used a higher cutoff for depression: $8 \%$ of women with diagnosed MS had severe depression compared to $4 \%$ in the reference group, with adjusted OR (aOR) 2.2 (95\% CI, $1.2-4.2)$.

There was no difference in depression point prevalence 6 months after birth between women diagnosed with MS and the reference group. However, among the women with MS who were depressed in the third trimester, $77 \%$ of those responding to both questionnaires $(\mathrm{n}=13)$ were still depressed 6 months postpartum compared to $38 \%$ in the reference group (aOR, 5.2; 95\% CI, 1.4-18.8). Nevertheless, the proportion of women who had recovered from perinatal depression 18 months postpartum was similar; $52 \%$ recovery for women with MS diagnosis before pregnancy and $61 \%$ for women in the reference group (aOR, 1.3; 95\% CI, 0.5-2.9).

Among the women with perinatal depression, this represented their first-ever episode of depression in 50\% with diagnosed MS and in $51 \%$ of the reference group (aOR, 1.3; 95\% CI, 0.6-3.2).

Self-reported use of antidepressants during pregnancy did not differ between the groups. Among the women diagnosed with 
Table 1 Characteristics of Participants at Inclusion in the Mother, Father, and Child Cohort Study

\begin{tabular}{|c|c|c|c|c|}
\hline \multirow[b]{2}{*}{ Demographic characteristics } & \multirow[b]{2}{*}{$\begin{array}{l}\text { Group 1: MS } \\
\text { diagnosed before } \\
\text { pregnancy, } n=140\end{array}$} & \multicolumn{2}{|c|}{ MS diagnosed after pregnancy } & \multirow[b]{2}{*}{$\begin{array}{l}\text { Reference group, } \\
n=111,627\end{array}$} \\
\hline & & $\begin{array}{l}\text { Group 2: Symptom } \\
\text { onset before pregnancy, } \\
n=98\end{array}$ & $\begin{array}{l}\text { Group 3: Symptom } \\
\text { onset after pregnancy, } \\
n=308\end{array}$ & \\
\hline Age at inclusion, $y$ & $31(4)^{n}$ & $30(4)$ & $28(5)^{n}$ & $30(5)$ \\
\hline Parity $^{a}$ & $1(0-4)$ & $1(0-4)$ & $1(0-3)$ & $1(0-4)$ \\
\hline Low household income ${ }^{b}$ & $5(4)$ & $5(6)$ & $22(9)$ & $7,402(8)$ \\
\hline Maternal short education ${ }^{c}$ & $3(2)$ & $2(2)$ & $8(3)$ & $2,751(3)$ \\
\hline Single mother & $5(4)$ & $3(4)$ & $5(2)$ & $2,371(2)$ \\
\hline Unplanned pregnancy & $17(13)$ & $8(9)^{m}$ & $57(20)$ & $19,486(20)$ \\
\hline Comorbidity $^{\mathrm{d}}$ & $5(4)$ & $9(10)$ & $21(7)$ & $7,452(7)$ \\
\hline Social security disability ${ }^{e}$ & $22(17)^{n}$ & $0(0)$ & $8(3)$ & $1,653(2)$ \\
\hline Adverse life events $^{f}$ & $49(41)$ & $30(37)$ & $87(33)$ & $30,462(33)$ \\
\hline Adverse pregnancy events ${ }^{g}$ & $40(31)$ & $28(31)$ & $77(26)$ & $28,702(28)$ \\
\hline Previous anxiety/depression ${ }^{h}$ & $37(26)$ & $20(20)$ & $69(22)$ & $24,912(22)$ \\
\hline Physical/sexual abuse $^{\mathrm{i}}$ & $20(17)$ & $17(21)$ & $58(22)^{\mathrm{m}}$ & $15,484(17)$ \\
\hline Smoking in pregnancy & $13(11)$ & $14(18)^{\mathrm{m}}$ & $38(15)^{\mathrm{m}}$ & $8,405(9)$ \\
\hline Alcohol in pregnancy ${ }^{j}$ & $5(4)$ & $2(2)$ & $5(2)$ & $2,643(3)$ \\
\hline Prepregnancy BMI >25 & $43(34)$ & $30(35)$ & $101(37)^{\mathrm{m}}$ & $30,803(31)$ \\
\hline Depression/anxiety week $18^{k}$ & $20(16)$ & $6(7)$ & $38(14)$ & $10,682(11)$ \\
\hline \multicolumn{5}{|l|}{ MS characteristic } \\
\hline Age at diagnosis, $y$ & $26(5)$ & $34(6)$ & $37(6)$ & NA \\
\hline Years with/until MS diagnosis & $5(0$ to 21$)$ & $-4(-13$ to 0$)$ & $-8(-17$ to -1$)$ & NA \\
\hline Years since/until onset' of MS & $7(1$ to 21$)$ & $2(0$ to 15$)$ & $-6(-17$ to -1$)$ & NA \\
\hline Years from onset' to diagnosis & $1(0$ to 16$)$ & $8(0$ to 22$)$ & $1(0$ to 11$)$ & NA \\
\hline Type of MS & & & & NA \\
\hline RRMS & $115(82)$ & $91(93)$ & $298(97)$ & \\
\hline PPMS & $1(<1)$ & $4(4)$ & $4(1)$ & \\
\hline Unspecified & $24(17)$ & $3(3)$ & $6(2)$ & \\
\hline
\end{tabular}

Abbreviations: $\mathrm{BMI}=$ body mass index; $\mathrm{MS}$ = multiple sclerosis; $\mathrm{NA}=$ not applicable; PPMS = primary progressive multiple sclerosis; RRMS = relapsingremitting multiple sclerosis.

Women were divided into 3 groups defined by their MS status in pregnancy. The reference group consisted of all women without MS diagnosis during the follow-up period. The number may vary within the columns due to missing data. Categorical variables were compared with Pearson $\chi^{2}$ test or Fisher exact test. Continuous variables were analyzed with Student $t$ test when normally distributed and skewed data with the Mann-Whitney $U$ test. Values are mean (SD), median (range), or $\mathrm{n}(\%)$.

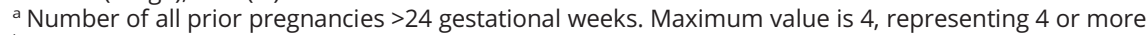

${ }^{b}$ Total household income $<60 \%$ of the cohort median income in the given measurement year.

${ }^{\mathrm{C}}$ Maternal short education $\leq 9$ years.

${ }^{d}$ Prepregnancy chronic diseases registered by health personnel in the Medical Birth Registry of Norway: asthma, prepregnancy hypertension, renal disease, rheumatoid arthritis, type 1 diabetes, or epilepsy.

e Permanent social security disability or work assessment allowance funded by the government.

${ }^{f} \geq 1$ of the following: problems at work/study, financial problems, divorce/separation/breakup, conflict with family or friends, severe injury or illness to the woman or a loved one, involvement in a severe traffic accident, fire or robbery, or death of a close relative or friend during the last 12 months and defining it as "painful or difficult."

${ }^{g}$ Prior history of stillbirth or miscarriages $>12$ weeks, prior or current preeclampsia, or first trimester vaginal bleeding.

${ }^{\mathrm{h}}$ Self-reported history of anxiety or positive screening on the lifetime history of major depression score.

' Physical or sexual abuse during childhood or adulthood. Questions adapted from the Abuse Assessment Screen.

'Alcohol consumption $\geq 1$ occasion per month during pregnancy.

${ }^{\mathrm{k}} \mathrm{A}$ combined score of depression and anxiety (Symptom Checklist 5) was used in pregnancy weeks 17-20.

'First MS symptom.

$\mathrm{m}$ Level of significance compared to the reference group $p<0.05$.

${ }^{\mathrm{n}}$ Level of significance compared to the reference group $p<0.001$ 
Table 2 Depression and Anxiety in Women With Multiple Sclerosis (MS) Diagnosed Before Pregnancy and During the Postpartum Period

\begin{tabular}{|c|c|c|c|c|c|c|c|}
\hline & \multicolumn{3}{|c|}{ MS diagnosed before pregnancy, $n=140$} & \multicolumn{3}{|c|}{ MS diagnosed postpartum, $\mathrm{n}=35$} & \multirow[b]{2}{*}{ Reference group, $n=111,627, n(\%)$} \\
\hline & $N(\%)$ & OR $(95 \% \mathrm{Cl})$ & $p$ Value & $\mathbf{N}(\%)$ & OR $(95 \% \mathrm{Cl})$ & $p$ Value & \\
\hline \multicolumn{8}{|l|}{ Depression } \\
\hline Third trimester $^{a}$ & $18(15)^{b}$ & $2.0(1.2-3.1)^{\mathrm{b}}$ & $0.006^{\mathrm{b}}$ & $0(0)^{\mathrm{b}}$ & - & $0.043^{b}$ & $8,410(9)$ \\
\hline 6 months postpartum & $16(14)$ & $1.5(0.8-2.5)$ & 0.182 & $7(23)^{b}$ & $3.1(1.3-7.2)^{b}$ & $0.010^{\mathrm{b}}$ & $8,246(10)$ \\
\hline 18 months postpartum & $15(17)$ & $1.4(0.8-2.5)$ & 0.279 & $10(42)^{b}$ & $5.0(2.1-11.9)^{b}$ & $<0.001^{\mathrm{b}}$ & $8,333(13)$ \\
\hline \multicolumn{8}{|l|}{ Anxiety } \\
\hline Third trimester ${ }^{a}$ & $5(4)$ & $0.8(0.4-2.0)$ & 0.705 & $1(3)$ & $0.5(0.1-4.1)$ & 0.552 & $5,089(6)$ \\
\hline 6 months postpartum & $4(4)$ & $0.8(0.3-2.2)$ & 0.692 & $3(10)$ & $2.4(0.7-7.7)$ & 0.149 & $4,058(5)$ \\
\hline 18 months postpartum & $6(7)$ & $1.4(0.6-3.2)$ & 0.419 & $0(0)$ & - & 0.640 & $3,591(6)$ \\
\hline
\end{tabular}

Point prevalence of depression and anxiety from pregnancy until 18 months postpartum is shown. Adjusted $p$ values and odds ratios (ORs) with $95 \%$ confidence intervals (Cls) for depression and anxiety in women diagnosed with MS before pregnancy and in the postpartum period compared to women without MS are shown. The number ( $n$ ) may vary within the columns because of missing data. Depression and anxiety are defined as Hopkins Symptom Checklist (SCL-4D and SCL-4A, respectively) mean $>1.75$. Estimates are adjusted for age, parity, overweight (body mass index $>25$ ), and adverse socioeconomic factors (single mother, low household income $<60 \%$ of median, and short education $\leq 9$ years).

a Pregnancy week 30.

b Statistically significant.

MS and depression in the third trimester, $17 \%$ had used antidepressants up to this time in pregnancy, compared to $12 \%$ of the depressed women in the reference group (aOR, 1.2; $95 \%$ CI, 0.4-4.5).

There were no differences in point prevalence of anxiety between women with diagnosed MS and the reference group during and after pregnancy.

\section{Secondary Outcome}

The backward stepwise logistic regression analysis identified several predictors for depression in the third trimester in women diagnosed with MS before pregnancy (table 3). Interaction analyses indicated a synergistic effect between MS and adverse socioeconomic factors and MS and history of sexual or physical abuse on the risk of depression. Previous depression or anxiety did not modify the effect of MS on depression. Recent MS diagnosis, MS type, and receiving disability benefits were not predictors for depression (data available from Dryad, table e-1, doi.org/10.5061/dryad. g4f4qrfpkv).

\section{Women Diagnosed With MS After Pregnancy}

Women diagnosed with MS after pregnancy with symptom onset before pregnancy (group 2) did not have increased frequency of depression or anxiety in the perinatal period (table 4).

Table 3 Predictors for Third Trimester Depression in Women With Multiple Sclerosis (MS) Diagnosed Before Pregnancy and Women Without MS

\begin{tabular}{|c|c|c|c|c|c|}
\hline \multirow[b]{2}{*}{ Predictor } & \multicolumn{2}{|c|}{ MS $(n=140)$} & \multicolumn{2}{|c|}{ Reference group $(n=111,627)$} & \multirow{2}{*}{$\begin{array}{l}\text { Interaction term } \\
\text { MS } \times \text { predictor, } \\
p \text { value }\end{array}$} \\
\hline & $p$ Value & OR (95\% Cl) (multivariable) & $p$ Value & OR (95\% Cl) (multivariable) & \\
\hline Adverse socioeconomic factors ${ }^{a}$ & 0.006 & $6.0(1.7-28.0)$ & $<0.001$ & $1.9(1.7-2.0)$ & 0.061 \\
\hline Sexual/physical abuse ${ }^{\text {b }}$ & 0.003 & $5.5(1.8-17.5)$ & $<0.001$ & $1.8(1.7-1.9)$ & 0.068 \\
\hline Previous depression/anxietyc & 0.009 & $4.6(1.5-14.6)$ & $<0.001$ & $3.6(3.4-3.8)$ & 0.692 \\
\hline
\end{tabular}

Odds ratios (ORs) with 95\% confidence intervals (Cls) for predictors of depression in the third trimester in women with MS diagnosis before pregnancy and women in the reference group are shown. We manually performed a backward stepwise logistic regression analysis within the group of women with MS diagnosed before pregnancy, with third trimester depression as the dependent variable and 17 independent variables as potential predictors (data available from Dryad, table e-1, doi.org/10.5061/dryad.g4f4qrfpkv). The alpha to enter the multivariate model was $\leq 0.1$ and $\geq 0.05$ for variable removal. Predictors remaining in the model are shown here. The final model was subsequently run on the reference group to compare estimates of ORs. We performed separate backward stepwise logistic regression analyses on the reference group (data available from Dryad, figure e-1). The remaining predictors for the MS population were included as interaction terms in logistic regression analyses on the entire population with third trimester depression as the dependent variable with adjustment for age, parity, socioeconomic factors, and prepregnancy body mass index $>25$.

a Single mother, low household income $<60 \%$ of median, or short education $\leq 9$ years.

b Physical or sexual abuse during childhood or adulthood. Questions adapted from the Abuse Assessment Screen.

c Self-reported history of anxiety or positive screening on the lifetime history of major depression score. 
Table 4 Perinatal Depression and Anxiety in Women Diagnosed With Multiple Sclerosis (MS) After Pregnancy

\begin{tabular}{|c|c|c|c|c|c|c|c|}
\hline & \multicolumn{2}{|c|}{ Symptom onset before pregnancy, $n=98$} & \multicolumn{4}{|c|}{ Symptom onset after pregnancy, $n=308$} & \multirow{3}{*}{$\begin{array}{l}\text { Reference group, } \\
\mathrm{n}=111,627, \mathrm{n}(\%)\end{array}$} \\
\hline & \multirow[b]{2}{*}{ N (\%) } & \multirow[b]{2}{*}{ OR $(95 \% \mathrm{Cl})$} & \multicolumn{2}{|c|}{$\begin{array}{l}\leq 5 \text { years after } \\
\text { pregnancy, } n=136\end{array}$} & \multicolumn{2}{|c|}{$\begin{array}{l}>5 \text { years after } \\
\text { pregnancy, }{ }^{a} n=172\end{array}$} & \\
\hline & & & N (\%) & OR $(95 \% \mathrm{CI})$ & N (\%) & OR $(95 \% \mathrm{CI})$ & \\
\hline \multicolumn{8}{|l|}{ Depression } \\
\hline Third trimester ${ }^{b}$ & $5(6)$ & $0.5(0.2-1.4)$ & $17(14)^{c}$ & $1.9(1.1-3.1)^{c}$ & $16(11)$ & $1.2(0.7-2.0)$ & $8,410(9)$ \\
\hline 6 months postpartum & $9(11)$ & $1.3(0.6-2.6)$ & $16(14)$ & $1.8(0.99-3.1)$ & $17(12)$ & $1.2(0.7-2.0)$ & $8,246(10)$ \\
\hline \multicolumn{8}{|l|}{ Anxiety } \\
\hline Third trimesterb $^{b}$ & $3(4)$ & $0.7(0.2-2.2)$ & $11(9)^{\mathrm{c}}$ & $2.0(1.1-3.7)^{c}$ & $8(6)$ & $0.7(0.3-1.6)$ & $5,089(6)$ \\
\hline 6 months postpartum & $4(5)$ & $1.1(0.4-3.1)$ & $7(6)$ & $1.3(0.6-3.0)$ & $11(8)$ & $1.8(0.9-3.2)$ & $4,058(5)$ \\
\hline \multicolumn{8}{|c|}{$\begin{array}{l}\text { The number (n) may vary within the columns due to missing data. } \\
\text { Point prevalence of depression and anxiety from pregnancy until } 6 \text { months postpartum is shown. Adjusted } p \text { values and odds ratios (ORs) with } 95 \% \\
\text { confidence intervals (Cls) for depression and anxiety in women diagnosed with MS after pregnancy compared to a reference group of women without MS are } \\
\text { shown. Depression and anxiety are defined as Hopkins Symptom Checklist (SCL-4D and SCL-4A, respectively) mean }>1.75 \text {. Estimates are adjusted for age, } \\
\text { parity, overweight (body mass index }>25 \text { ), and adverse socioeconomic factors (single mother, low income }<60 \% \text { of median, and short education } \leq 9 \text { years). } \\
\text { a } 6-17 \text { years after pregnancy. } \\
\text { b Pregnancy week } 30 \text {. } \\
\text { ' Statistically significant. }\end{array}$} \\
\hline
\end{tabular}

Among women with symptom onset after pregnancy (group 3), those with their first MS symptom within 5 years after pregnancy $(\mathrm{n}=136)$ had higher frequency of depression and anxiety in the third trimester compared to the reference group (depression: $14 \%$ vs $9 \%$, anxiety: $9 \%$ vs $6 \%$ ) (table 4). In contrast, women with more than 5 years to onset of symptoms $(\mathrm{n}=172)$ did not have higher frequency of depression or anxiety at any assessment in the perinatal period.

\section{Women Diagnosed With MS Postpartum}

Thirty-five women were diagnosed with MS during the 18month postpartum period (figure 1). Although none of these was depressed at the assessment in the third trimester, they had a higher frequency of depression compared to the reference group both at 6 months ( $23 \%$ vs $10 \%)$ and at 18 months postpartum ( $42 \%$ vs $13 \%$ ) (table 2 ). There were no differences in point prevalences of anxiety between women with postpartum MS diagnosis and the reference group. Median time from symptom onset to diagnosis was 2 years (range $0-12$ ) in women with postpartum depression in this group, compared to 1 year (range $0-12$ ) for this MS group as a whole.

Women in the reference group who were diagnosed with other chronic diseases in the postpartum period $(\mathrm{n}=2,640)$ more often had postpartum depression compared to the remaining "healthy" proportion of the reference group, but numerically lower than for women with postpartum MS diagnosis (figure 3). The aORs of postpartum depression in women diagnosed with MS postpartum compared to women diagnosed with other chronic diseases in the same period was 1.5 (95\% CI, 0.6-3.4) at 6 months and 1.9 (95\% CI, 0.8-4.2) 18 months postpartum.

\section{Discussion}

Our study found increased risk of depression during pregnancy in women with an established MS diagnosis. Furthermore, women with MS and depression in pregnancy had more prolonged depressive symptoms, lasting into the postpartum period. However, the prognosis for recovery was similar 18 months postpartum. Women who were diagnosed with MS in the postpartum period had a high risk of postpartum depression.

Figure 3 Perinatal Depression in Women Diagnosed With Multiple Sclerosis (MS) or Other Chronic Disease in the Postpartum Period

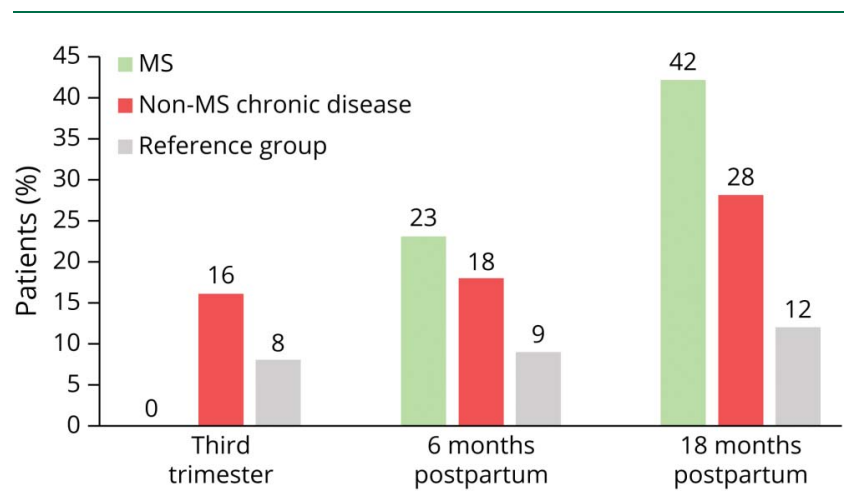

Point prevalence of depression from pregnancy week 30 until 18 months postpartum in women who were diagnosed with MS $(n=35)$ or another chronic disease $(n=2,640)$ in the 18 -month postpartum period. Women without MS or another postpartum chronic diagnosis $(n=108,987)$ represents the reference group. Depression is defined as Hopkins Symptom Checklist 4D mean $>1.75$. N values are given for the first assessment and are later lower due to missing data. Women who were pregnant 18 months postpartum were excluded (figure 2). 
The use of validated questionnaires and a population-based design in the current study extends previous knowledge on perinatal depression in MS. We have identified one other study on prevalence and risk estimations of perinatal depression in people with MS. This other population-based study found a $26 \%$ prevalence of perinatal depression or anxiety in 255 women with MS, compared to $21 \%$ in 904 women without MS (OR, 1.28; 95\% CI, 0.99-1.65). ${ }^{7}$ Our point prevalence figures were lower ( $15 \%$ vs $9 \%$ ), whereas the risk estimate for depression in the third trimester for women with MS was higher in our study. The estimates are not strictly comparable due to different methodology. We evaluated depressive and anxiety symptoms separately and used several assessments of point prevalence instead of period prevalence. The previous study used diagnostic codes in addition to antidepressant and anxiolytic prescriptions as proxies for depression and anxiety.

The increased occurrence of depression during pregnancy in women with an established MS diagnosis could be explained by several factors. Perinatal depression is linked to dysregulation of the maternal hypothalamic-pituitary-adrenal (HPA) axis. ${ }^{30,31}$ The HPA axis is also involved in the mechanisms of MS. ${ }^{32}$ The knowledge of having a severe and potentially progressive disease may cause psychological distress. Uncertainty and lack of hope are shown to be independent predictors for depression in MS, regardless of disability status. ${ }^{33}$ In addition, depression might be caused by inflammation ${ }^{3}$ or manifest lesions in the brain. ${ }^{34}$ All these mechanisms can interact or have reciprocal effects.

In contrast to women with an established MS diagnosis before pregnancy, women who were diagnosed with MS postpartum had a substantially increased risk of postpartum depression. Depressive symptoms in these women could be triggered by disease awareness in a vulnerable period when caring for a newborn baby. Women who were diagnosed with other chronic diseases in the postpartum period also had higher occurrence of depression, but not as marked as for women diagnosed with MS. Many of these women with a recent MS diagnosis probably had ongoing disease activity and inflammation, which may have contributed to the depressive symptoms. 3,35

We found low risk estimates for perinatal anxiety for women with established MS. Previous studies have shown that depression and anxiety probably have diverse attributable factors and mechanisms in MS, which may explain why the risk estimates differed. One study found correlation between inflammation and social and state anxiety, while trait anxiety was associated with disease duration. ${ }^{3}$ Depression, but not anxiety, has been associated with subsequent disability progression. ${ }^{36}$ Another study found an association between depression and brain atrophy, but no association between anxiety and atrophy. ${ }^{34}$

Key predictors for pregnancy-related depression in women with established MS in our study were adverse socioeconomic factors, a history of sexual or physical abuse, and depression or anxiety prior to pregnancy. The same predictors for perinatal depression have previously been found in women with epilepsy, ${ }^{24}$ and are also known predictors for perinatal depression in the general maternal population. ${ }^{25,26}$ However, the interaction analyses indicated a synergistic effect between MS and adverse socioeconomic status and between MS and a history of sexual or physical abuse. This means that having experienced abuse or having adverse socioeconomic status seemed to increase the risk of depression substantially more in women with MS than in women without MS. Accordingly, women with these risk factors need special attention and follow-up.

Perinatal depression in women with MS requires intervention, as it reduces quality of life, often leads to paternal depression, ${ }^{37}$ and reduces adherence to MS treatment. ${ }^{38}$ It may also influence the mother-infant bond negatively, ${ }^{39}$ and is associated with higher risk of psychiatric disorders in children. $^{7,8}$

We found that women with MS symptom onset within 5 years after pregnancy had increased risk of both depression and anxiety during pregnancy. Conversely, women with more than 5 years until onset of MS symptoms did not have any increased risk. Depression and anxiety are recognized as parts of MS prodromal syndrome. ${ }^{11,12}$ Previous studies in nonpregnant MS populations have shown increased occurrence of depression and anxiety 2 years before MS diagnosis ${ }^{40}$ and up to 5-10 years before the first demyelinating event. ${ }^{12,13}$ The risk gradually increased closer to the year of the first event.

Women who were yet to be diagnosed with MS who had already experienced their first MS-associated symptom did not show any increased frequencies of depression or anxiety in pregnancy. Of note, they had the lowest rate of unplanned pregnancies, which may protect against perinatal depression. ${ }^{41}$ Their median time from MS onset to diagnosis was 8 years compared to only 1 year in the other 2 MS groups. This suggests that this group had a different disease course with milder onset symptoms, and thus later diagnostic attention.

Strengths of our study include a large and detailed populationbased dataset. Our database linkage resulted in a unique study design that gave the opportunity to compare pregnant women with MS in different stages of the disease both with the general population and with women who contracted other chronic diseases postpartum. The MS diagnosis was thoroughly validated in a nationwide collaboration with local neurology departments. The data were prospectively collected with longitudinal measurements of depression and anxiety with validated screening tools. ${ }^{42}$ Sensitivity analyses confirmed that depression in women with established MS was independent of fatigue, and our findings were valid with higher cutoff for depression. The dropout rates among the depressed women in the different MS groups and the reference group were similar, which limits the possibility of attrition bias. 
There are some limitations to our study. Depression and anxiety were not diagnosed by a physician. However, anonymous questionnaires using the SCL screening tools have previously been shown to more accurately capture psychiatric symptoms than interviews. ${ }^{43}$ Screening positive on SCL subscales has been predictive of subsequent hospitalization with depression and dispensation of antidepressants. ${ }^{44}$ Women with psychological distress may have been less motivated to participate in the MoBa study. This potential bias could underestimate the depression prevalence, but should not influence the risk differences between women with and without MS. Hence, the exposure-outcome associations found in our study are generalizable to the maternal population. A moderate participation rate of $41 \%$ can result in a slightly selected sample, but is as expected from populationbased cohorts. ${ }^{45}$ A study on selection bias in the MoBa cohort found an underrepresentation of adverse socioeconomic exposure variables in the participating women, which may give biased estimates of exposure and outcome prevalence. ${ }^{46}$ Previous population-based studies in Norway with $90 \%$ participation rates have found $9 \%-11 \%$ prevalence of perinatal depression, scored with EPDS, from the second trimester in pregnancy into the postpartum period. ${ }^{47-49} \mathrm{We}$ found the same prevalence in our reference group. Thus, a potential selection bias seems to have minimal effect on the outcomes in our study. Due to personal data protection regulations, we received date of MS onset/diagnosis as well as birth year, but we did not know date of birth. Hence, we could not estimate the exact relation between MS onset and diagnosis to childbirth for a subgroup of patients. A few women may have been misclassified into the group "MS diagnosed after pregnancy with symptom onset before pregnancy." A total of 3-6 women in this group could have been diagnosed with MS in late pregnancy and a maximum of 25 women could have had their symptom onset during pregnancy. We had no information on MS severity such as the Expanded Disability Status Scale. Furthermore, our material lacks MRI data and clinical information on MS disease activity to assess effect on depression and its influence by inflammation. Breastfeeding may influence postpartum depression, ${ }^{50}$ but information on breastfeeding was not available in our dataset. We had limited information on medication, both antidepressants and MSspecific disease-modifying drugs. Further research that includes potential effects of these variables is necessary for the understanding of pathobiologic mechanisms in perinatal depression in MS.

The increased risk and prolonged duration of perinatal depression in women with MS shown in this study should lead to special attention with timely prevention and treatment. Clinicians should be especially aware of signs of depression in women diagnosed with MS in the postpartum period.

\section{Acknowledgment}

The Norwegian Mother, Father and Child Cohort study is supported by the Norwegian Ministry of Health and
Care Services and the Ministry of Education and Research. The authors thank Alok Bhan, MD (Department of Neurology, Stavanger University Hospital, Norway); Britt Bruland, CNS (Department of Neurology, Førde Hospital, Norway); Kathrine K. Lian, MD (Department of Neurology, St. Olavs Hospital, Trondheim, Norway); and Stephan Schüler, MD, PhD (Department of Neurology, Namsos Hospital, Norway) for contributing to data extraction and validation of MS diagnoses; and the participating families in Norway who take part in this ongoing cohort study.

\section{Study Funding}

The authors received research support from Novartis Norway, the Western Norway Regional Health Authority, and the University of Bergen. Neuro-SysMed is funded by the Norwegian Research Council grant 288164.

\section{Disclosure}

K. Eid has received an unrestricted research grant from Novartis. Ø. Torkildsen has received speaker honoraria from and served on scientific advisory boards for Biogen, Sanofi-Aventis, Merck, and Novartis. J. Aarseth reports no disclosures. H. Flemmen has received research grants and speaker honoraria from Biogen Idec and Novartis and has received speaker honoraria from Sanofi and Merck. T. Holmøy has received lecture fees and research grants from Biogen, Roche, Novartis, Merck, and Sanofi and is on the Medical Committee of the Norwegian MS Association. Å.R. Lorentzen reports no disclosures. K.M. Myhr has received unrestricted research grants to his institution; scientific advisory board and speaker honoraria from Almirall, Biogen, Genzyme, Merck, Novartis, Roche, and Teva; and has participated in clinical trials organized by Biogen, Merck, Novartis, and Roche. T. Riise reports no disclosures relevant to the manuscript. C.S. Simonsen has received an unrestricted research grant from Novartis and has received speaker honoraria from and served on scientific advisory boards for Sanofi, Merck, and Biogen Idec. C. Torkildsen has served on a scientific advisory board for Astra Zeneca. S. Wergeland has received speaker honoraria from and served on scientific advisory boards for Biogen, Alexion, Sanofi-Aventis, and Novartis. J.S. Willumsen has received an unrestricted research grant from Novartis. $\mathrm{N}$. Øksendal has received speaker and consultant honoraria from Biogen and has served on a scientific advisory board for Novartis. N.E. Gilhus has received speaker and consultant honoraria from UCB, RaPharma, Argenx, Octapharma, Alexion, Roche, and Merck. M.H. Bjørk has received research support, consultant honoraria, and speakers honoraria from Novartis and speakers honoraria from Teva, Lilly, and Allergan. Go to Neurology.org/N for full disclosures.

\section{Publication History}

Received by Neurology October 10, 2020. Accepted in final form March 11, 2021. 
Appendix Authors

\begin{tabular}{|c|c|c|}
\hline Name & Location & Contribution \\
\hline $\begin{array}{l}\text { Karine Eid, } \\
\text { MD }\end{array}$ & $\begin{array}{l}\text { University of Bergen and } \\
\text { Haukeland University } \\
\text { Hospital, Norway }\end{array}$ & $\begin{array}{l}\text { Analyzed and interpreted } \\
\text { the data, drafted and } \\
\text { revised the manuscript for } \\
\text { intellectual content, had full } \\
\text { access to all the data, } \\
\text { provided funding }\end{array}$ \\
\hline
\end{tabular}

\begin{tabular}{lll}
\hline $\begin{array}{l}\text { Øivind } \\
\text { Fredvik } \\
\begin{array}{l}\text { Torkildsen, } \\
\text { MD, PhD }\end{array}\end{array}$ & $\begin{array}{l}\text { University of Bergen and } \\
\text { Haukeland University } \\
\text { Hospital, Norway }\end{array}$ & $\begin{array}{l}\text { Data collection, revised the } \\
\text { manuscript for intellectual } \\
\text { content, final approval of } \\
\text { manuscript }\end{array}$ \\
\hline $\begin{array}{l}\text { Jan Aarseth, } \\
\text { PhD }\end{array}$ & $\begin{array}{l}\text { Haukeland University } \\
\text { Hospital, Bergen, Norway }\end{array}$ & $\begin{array}{l}\text { Data collection, revised the } \\
\text { manuscript for intellectual } \\
\text { content, final approval of } \\
\text { manuscript }\end{array}$
\end{tabular}

\begin{tabular}{ll}
\hline Heidi øyen & Telemark Hospital Trust, \\
Flemmen, & Skien, Norway \\
MD & \\
\end{tabular}

Data collection, revised the manuscript for intellectual content, final approval of manuscript

\begin{tabular}{ll}
\hline $\begin{array}{l}\text { Trygve } \\
\text { Holmøy, MD, } \\
\text { PhD }\end{array}$ & $\begin{array}{l}\text { Department of Neurology, } \\
\text { Akershus University } \\
\text { Hospital and University of } \\
\text { Oslo, Norway }\end{array}$ \\
\hline $\begin{array}{l}\text { Aslaug } \\
\text { Rudjord } \\
\text { Lorentzen, } \\
\text { MD, PhD }\end{array}$ & $\begin{array}{l}\text { Department of Neurology } \\
\text { and The Norwegian }\end{array}$ \\
& $\begin{array}{l}\text { National Advisory Unit on } \\
\text { Tick-borne diseases, } \\
\text { Sørlandet Hospital, } \\
\text { Norway }\end{array}$ \\
\hline
\end{tabular}

\begin{tabular}{ll}
\hline Kjell-Morten & University of Bergen and \\
Myhr, MD, & Haukeland University \\
PhD & Hospital, Norway
\end{tabular}

Data collection, revised the manuscript for intellectual content, final approval of manuscript

Data collection, revised the manuscript for intellectual content, final approval of manuscript

\section{Designed and}

conceptualized study, interpretation of the data, revised the manuscript for intellectual content, final approval of manuscript

\begin{tabular}{ll}
\hline Trond Riise, & University of Bergen and \\
PhD & Haukeland University \\
& Hospital, Norway
\end{tabular}

Designed and conceptualized study, interpretation of the data, revised the manuscript for intellectual content, final approval of manuscript

\begin{tabular}{|c|c|c|}
\hline $\begin{array}{l}\text { Cecilia } \\
\text { Simonsen, } \\
\text { MD }\end{array}$ & $\begin{array}{l}\text { Department of Neurology, } \\
\text { Vestre Viken Hospital Trust, } \\
\text { Norway }\end{array}$ & $\begin{array}{l}\text { Data collection, revised the } \\
\text { manuscript for intellectual } \\
\text { content, final approval of } \\
\text { manuscript }\end{array}$ \\
\hline $\begin{array}{l}\text { Cecilie } \\
\text { Fredvik } \\
\text { Torkildsen, } \\
\text { MD }\end{array}$ & $\begin{array}{l}\text { University of Bergen and } \\
\text { Stavanger University } \\
\text { Hospital, Norway }\end{array}$ & $\begin{array}{l}\text { Designed and } \\
\text { conceptualized study, } \\
\text { revised the manuscript for } \\
\text { intellectual content, final } \\
\text { approval of manuscript }\end{array}$ \\
\hline $\begin{array}{l}\text { Stig } \\
\text { Wergeland, } \\
\text { MD, PhD }\end{array}$ & $\begin{array}{l}\text { Haukeland University } \\
\text { Hospital, Bergen, Norway }\end{array}$ & $\begin{array}{l}\text { Data collection, revised the } \\
\text { manuscript for intellectual } \\
\text { content, final approval of } \\
\text { manuscript }\end{array}$ \\
\hline $\begin{array}{l}\text { Johannes } \\
\text { Sverre } \\
\text { Willumsen, } \\
\text { MD }\end{array}$ & $\begin{array}{l}\text { Møre og Romsdal Hospital } \\
\text { Trust, Molde, Norway }\end{array}$ & $\begin{array}{l}\text { Data collection, revised the } \\
\text { manuscript for intellectual } \\
\text { content, final approval of } \\
\text { manuscript }\end{array}$ \\
\hline $\begin{array}{l}\text { Nina } \\
\text { Øksendal, } \\
\text { MD }\end{array}$ & $\begin{array}{l}\text { Nordland Hospital Trust, } \\
\text { Bodø, Norway }\end{array}$ & $\begin{array}{l}\text { Data collection, revised the } \\
\text { manuscript for intellectual } \\
\text { content, final approval of } \\
\text { manuscript }\end{array}$ \\
\hline
\end{tabular}

Appendix (continued)

\begin{tabular}{lll}
\hline Name & Location & Contribution \\
\hline $\begin{array}{l}\text { Nils Erik } \\
\text { Gilhus, MD } \\
\text { PhD }\end{array}$ & $\begin{array}{l}\text { University of Bergen and } \\
\text { Haukeland University } \\
\text { Hospital, Norway }\end{array}$ & $\begin{array}{l}\text { Design and conceptualized } \\
\text { study, interpreted the data, } \\
\text { revised the manuscript for } \\
\text { intellectual content, } \\
\text { provided funding }\end{array}$ \\
\hline $\begin{array}{l}\text { Marte- } \\
\text { Helene Bjørk, } \\
\text { MD PhD }\end{array}$ & $\begin{array}{l}\text { University of Bergen and } \\
\text { Hospital, Norway }\end{array}$ & $\begin{array}{l}\text { Design and conceptualized } \\
\text { study, interpreted the data, } \\
\text { revised the manuscript for } \\
\text { intellectual content, had full } \\
\text { access to all the data, } \\
\text { provided funding }\end{array}$ \\
\hline
\end{tabular}

\section{References}

1. Boeschoten RE, Braamse AMJ, Beekman ATF, et al. Prevalence of depression and anxiety in multiple sclerosis: a systematic review and meta-analysis. J Neurol Sci. 2017; 372:331-341.

2. Patten SB, Marrie RA, Carta MG. Depression in multiple sclerosis. Int Rev Psychiatry. 2017;29(5):463-472.

3. Rossi S, Studer V, Motta C, et al. Neuroinflammation drives anxiety and depression in relapsing-remitting multiple sclerosis. Neurology. 2017;89(13):1338-1347.

4. World Health Organization. International Statistical Classification of Diseases, 10th Revision. World Health Organization: 2004.

5. National Institute for Health and Care Excellence. Antenatal and Postnatal Mental Health, Guideline 192. 2014. Accessed January 7, 2021. nice.org.uk/guidance/cg192/ chapter/1-recommendations.

6. O’Hara MW, Wisner KL. Perinatal mental illness: definition, description and aetiology. Best Pract Res Clin Obstet Gynaecol. 2014;28(1):3-12.

7. Razaz N, Tremlett H, Marrie RA, Joseph KS. Peripartum depression in parents with multiple sclerosis and psychiatric disorders in children. Mult Scler. 2016;22(14): 1830-1840.

8. Razaz N, Tremlett H, Boyce T, Guhn M, Marrie RA, Joseph KS. Incidence of mood or anxiety disorders in children of parents with multiple sclerosis. Paediatr Perinat Epidemiol. 2016;30(4):356-366.

9. Madigan S, Oatley $\mathrm{H}$, Racine $\mathrm{N}$, et al. A meta-analysis of maternal prenatal depression and anxiety on child socioemotional development. J Am Acad Child Adolesc Psychiatry. 2018;57(9):645-657.

10. Razaz N, Joseph KS, Boyce WT, et al. Children of chronically ill parents: relationship between parental multiple sclerosis and childhood developmental health. Mult Scler. 2016;22(11):1452-1462.

11. Wijnands JMA, Kingwell E, Zhu F, et al. Health-care use before a first demyelinating event suggestive of a multiple sclerosis prodrome: a matched cohort study. Lancet Neurol. 2017;16(6):445-451.

12. Disanto G, Zecca C, MacLachlan S, et al. Prodromal symptoms of multiple sclerosis in primary care. Ann Neurol. 2018;83(6):1162-1173.

13. Wijnands JM, Zhu F, Kingwell E, et al. Five years before multiple sclerosis onset: phenotyping the prodrome. Mult Scler. 2019;25(8):1092-1101.

14. Magnus P, Birke C, Vejrup K, et al. Cohort profile update: the Norwegian Mother and Child Cohort Study (MoBa). Int J Epidemiol. 2016;45(2):382-388.

15. Myhr KM, Grytten N, Torkildsen O, Wergeland S, Bo L, Aarseth JH. The Norwegian Multiple Sclerosis Registry and Biobank. Acta Neurol Scand. 2015; 132(199):24-28.

16. Benjaminsen E, Myhr KM, Grytten N, Alstadhaug KB. Validation of the multiple sclerosis diagnosis in the Norwegian Patient Registry. Brain Behav. 2019;9(11): e01422.

17. Thompson AJ, Banwell BL, Barkhof F, et al. Diagnosis of multiple sclerosis: 2017 revisions of the McDonald criteria. Lancet Neurol. 2018;17(2):162-173.

18. Nettelbladt P, Hansson L, Stefansson CG, Borgquist L, Nordstrom G. Test characteristics of the Hopkins symptom check list-25 (HSCL-25) in Sweden, using the present state examination (PSE-9) as a caseness criterion. Soc Psychiatry Psychiatr Epidemiol. 1993;28(3):130-133.

19. Strand BH, Dalgard OS, Tambs K, Rognerud M. Measuring the mental health status of the Norwegian population: a comparison of the instruments SCL-25, SCL-10, SCL-5 and MHI-5 (SF-36). Nordic J Psychiatry. 2003;57(2):113-118.

20. Tambs K, Moum T. How well can a few questionnaire items indicate anxiety and depression? Acta Psychiatr Scand. 1993;87(5):364-367.

21. Winokur A, Winokur DF, Rickels K, Cox DS. Symptoms of emotional distress in a family planning service: stability over a four-week period. Br J Psychiatry. 1984;144: 395-399.

22. Cox JL, Holden JM, Sagovsky R. Detection of postnatal depression: development of the 10-item Edinburgh Postnatal Depression Scale. Br J Psychiatry. 1987;150:782-786.

23. Solberg O, Dale MT, Holmstrom H, Eskedal LT, Landolt MA, Vollrath ME. Emotional reactivity in infants with congenital heart defects and maternal symptoms of postnatal depression. Arch Womens Ment Health. 2011;14(6):487-492. 
24. Bjork MH, Veiby G, Reiter SC, et al. Depression and anxiety in women with epilepsy during pregnancy and after delivery: a prospective population-based cohort study on frequency, risk factors, medication, and prognosis. Epilepsia. 2015;56(1):28-39.

25. Howard LM, Molyneaux E, Dennis CL, Rochat T, Stein A, Milgrom J. Nonpsychotic mental disorders in the perinatal period. Lancet. 2014;384(9956): 1775-1788.

26. Norhayati MN, Hazlina NH, Asrenee AR, Emilin WM. Magnitude and risk factors for postpartum symptoms: a literature review. J Affect Disord. 2015;175:34-52.

27. McFarlane J, Parker B, Soeken K, Bullock L. Assessing for abuse during pregnancy: severity and frequency of injuries and associated entry into prenatal care. JAMA. 1992; 267:3176-3178.

28. Kendler KS, Neale MC, Kessler RC, Heath AC, Eaves LJ. The lifetime history of major depression in women: reliability of diagnosis and heritability. Arch Gen Psychiatry. 1993;50(11):863-870.

29. Rooney S, Wood L, Moffat F, Paul L. Prevalence of fatigue and its association with clinical features in progressive and non-progressive forms of multiple sclerosis. Mult Scler Relat Disord. 2019;28:276-282.

30. Glynn LM, Davis EP, Sandman CA. New insights into the role of perinatal HPA-axis dysregulation in postpartum depression. Neuropeptides. 2013;47(6):363-370.

31. Rich-Edwards JW, Mohllajee AP, Kleinman K, et al. Elevated midpregnancy corticotropin-releasing hormone is associated with prenatal, but not postpartum, maternal depression. J Clin Endocrinol Metab. 2008;93(5):1946-1951.

32. Anagnostouli M, Markoglou N, Chrousos G. Psycho-neuro-endocrino-immunologic issues in multiple sclerosis: a critical review of clinical and therapeutic implications. Hormones. 2020;19(4):485-496.

33. Lynch SG, Kroencke DC, Denney DR. The relationship between disability and depression in multiple sclerosis: the role of uncertainty, coping, and hope. Mult Scler. 2001;7(6):411-416.

34. Zorzon M, de Masi R, Nasuelli D, et al. Depression and anxiety in multiple sclerosis: a clinical and MRI study in 95 subjects. J Neurol. 2001;248(5):416-421.

35. Dantzer R, O'Connor JC, Freund GG, Johnson RW, Kelley KW. From inflammation to sickness and depression: when the immune system subjugates the brain. Nat Rev Neurosci. 2008;9(1):46-56.

36. McKay KA, Tremlett H, Fisk JD, et al. Psychiatric comorbidity is associated with disability progression in multiple sclerosis. Neurology. 2018;90(15):e1316-e1323.
37. Letourneau NL, Dennis CL, Benzies K, et al. Postpartum depression is a family affair: addressing the impact on mothers, fathers, and children. Issues Ment Health Nurs. 2012;33(7):445-457.

38. Mohr DC, Goodkin DE, Likosky W, Gatto N, Baumann KA, Rudick RA. Treatment of depression improves adherence to interferon beta-1b therapy for multiple sclerosis. Arch Neurol. 1997;54(5):531-533.

39. Rossen L, Mattick RP, Wilson J, et al. Mother-infant bonding and emotional availability at 12 -months of age: the role of early postnatal bonding, maternal substance use and mental health. Matern Child Health J. 2019;23(12):1686-1698.

40. Hoang H, Laursen B, Stenager EN, Stenager E. Psychiatric co-morbidity in multiple sclerosis: the risk of depression and anxiety before and after MS diagnosis. Mult Scler. 2016;22(30):347-353.

41. Faisal-Cury A, Menezes PR, Quayle J, Matijasevich A. Unplanned pregnancy and risk of maternal depression: secondary data analysis from a prospective pregnancy cohort. Psychol Health Med. 2017;22(1):65-74.

42. Lundin A, Hallgren M, Forsell Y. The validity of the Symptom Checklist depression and anxiety subscales: a general population study in Sweden. J Affect Disord. 2015;183:247-252

43. Moum T. Mode of administration and interviewer effects in self-reported symptoms of anxiety and depression. Soc Indic Res. 1998;45(1-3):279-318.

44. Magnusson Hanson LL, Westerlund H, Leineweber C, et al. The Symptom Checklist-core depression (SCL-CD6) scale: psychometric properties of a brief six item scale for the assessment of depression. Scand J Public Health. 2014;42(1):82-88.

45. Nohr EA, Frydenberg M, Henriksen TB, Olsen J. Does low participation in cohort studies induce bias? Epidemiology. 2006;17(4):413-418.

46. Nilsen RM, Vollset SE, Gjessing HK, et al. Self-selection and bias in a large prospective pregnancy cohort in Norway. Paediatr Perinat Epidemiol. 2009;23(6):597-608.

47. Eberhard-Gran M, Eskild A, Tambs K, Samuelsen SO, Opjordsmoen S. Depression in postpartum and non-postpartum women: prevalence and risk factors. Acta Psychiat Scand. 2002;106(6):426-433.

48. Eberhard-Gran M, Tambs K, Opjordsmoen S, Skrondal A, Eskild A. Depression during pregnancy and after delivery: a repeated measurement study. J Psychosom Obstet Gynaecol. 2004;25(1):15-21.

49. Glavin K, Smith L, Sorum R. Prevalence of postpartum depression in two municipalities in Norway. Scand J Caring Sci. 2009;23(4):705-710.

50. Dias CC, Figueiredo B. Breastfeeding and depression: a systematic review of the literature. J Affect Disord. 2015;171:142-154. 


\section{Neurology}

\section{Perinatal Depression and Anxiety in Women With Multiple Sclerosis: A Population-Based Cohort Study}

Karine Eid, Øivind Fredvik Torkildsen, Jan Aarseth, et al.

Neurology 2021;96;e2789-e2800 Published Online before print April 21, 2021

DOI 10.1212/WNL.0000000000012062

\section{This information is current as of April 21, 2021}

\section{Updated Information \&} Services

References

Citations

Subspecialty Collections

Permissions \& Licensing

Reprints including high resolution figures, can be found at: http://n.neurology.org/content/96/23/e2789.full

This article cites 48 articles, 4 of which you can access for free at: http://n.neurology.org/content/96/23/e2789.full\#ref-list-1

This article has been cited by 2 HighWire-hosted articles: http://n.neurology.org/content/96/23/e2789.full\#\#otherarticles

This article, along with others on similar topics, appears in the following collection(s):

Depression

http://n.neurology.org/cgi/collection/depression

Multiple sclerosis

http://n.neurology.org/cgi/collection/multiple_sclerosis

Information about reproducing this article in parts (figures,tables) or in its entirety can be found online at:

http://www.neurology.org/about/about_the_journal\#permissions

Information about ordering reprints can be found online:

http://n.neurology.org/subscribers/advertise

Neurology ${ }^{\circledR}$ is the official journal of the American Academy of Neurology. Published continuously since 1951, it is now a weekly with 48 issues per year. Copyright Copyright (C) 2021 The Author(s). Published by Wolters Kluwer Health, Inc. on behalf of the American Academy of Neurology.. All rights reserved. Print ISSN: 0028-3878. Online ISSN: 1526-632X.

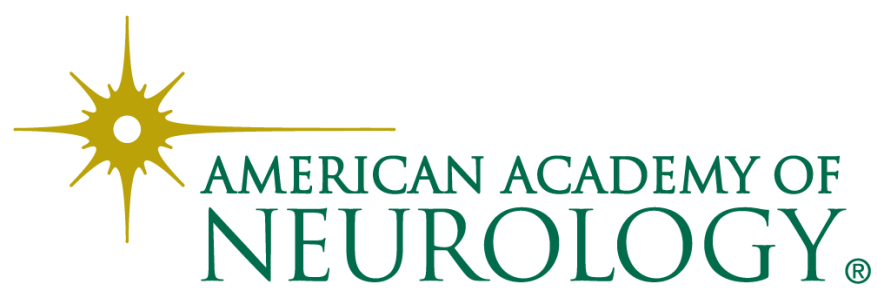

